\title{
Parallel lines or divergent trajectories? A response to the other contributions
}

\section{Ewart Keep $^{\mathrm{a}}$}

${ }^{a}$ Department of Education, University of Oxford, Oxford, United Kingdom

Contact: Ewart Keep ewart.keep@education.ox.ac.uk

Ewart Keep holds the Chair in education, training and skills at the Department of Education, Oxford University.

https://orcid.org/0000-0001-5687-7993

He is Director of the Centre on Skills, Knowledge \& Organisational Performance. Current research interests include the impact of digitalisation and AI on employment and skills, and the evolution of local industrial strategies and skills policies within Mayoral Combined Authorities.

\section{Disclosure statement}

No potential conflicts of interest were reported by the author 


\section{Parallel lines or divergent trajectories? A response to the other contributions}

This article provides a response to the other contributions in this special issue, and explores the range and scale of the opportunities for policy learning across the four UK nations. It addresses the importance of locating FE and skills policy within wider national policy contexts, national choices between markets and systems and the wider implications of these choices, and the vexed role of employers. Behind these lie three over-arching questions that are then interrogated - have we arrived at a moment when we can conceive of the UK as a policy learning laboratory, is this laboratory open for expansive policy learning, and who might be working in it?

Keywords: policy laboratory, policy learning, markets, systems, devolution. 


\section{Introduction}

This article offers a response to the other contributions in this edition. The aim is to address a small number of key issues that are raised by the various contributions rather than respond to every point. What follows draws on research on devolution and marketisation in FE undertaken by the Centre on Skills, Knowledge and Organisational Performance (SKOPE) and the Association of Colleges (AoC) for the Further Education Trust for Leadership (FETL), as well as on a range of focus groups and seminars run for senior college management and governance teams in a number of English colleges, and on the author's past membership of the joint Scottish Funding Council (SFC)/Skills Development Scotland (SDS) Joint Skills Committee, and current membership of the Scottish Government's Labour Market Strategy Group (LMSG).

At the outset it is important to echo the point made by James (this volume) that devolution is an evolving process. None of the devolved nations have yet reached a 'steady state' in their policy trajectories and in the evolution of the resultant implications that these trajectories have for relationships with each other and the UK government. The articles in this special edition offer fascinating snapshots of the present, and a review of how this point was reached, but future developments, especially in England, are much harder to foresee, not least as the exercise has taken place in the shadow of Brexit - the full implications of which in political, economic and constitutional terms are as yet unknowable. A change in the political complexion of UK government could, in one direction lead to an era of for-profit public education (see Kwarteng, 2015), and in the other, to an abandonment of markets in education and the (re-) introduction of some form of local democratic accountability as promised under Labour's outline proposals for a National Education Service.

This response addresses a number of themes and issues: the importance of locating FE and skills policy within wider national policy contexts, national choices between markets and systems and the wider implications of these choices, and the vexed role of employers. Behind these lie three overarching questions - have we arrived at a moment when we can conceive of the UK as a policy learning laboratory, is this laboratory open for expansive policy learning, and who might be working in it?

\section{Themes and issues}

\section{The importance of the broader national policy contexts}

One of the dangers of studying policies concerning a segment of educational provision, or even education more generally, is that the wider ideological and policy context can become distant and even marginalised. As Hodgson et al (this volume) observe, across the four countries there are a set of common vocational education and training policy issues and challenges (apprenticeship expansion, the use of the apprenticeship levy funds, the role and status of vocational education, and the purposes 
and functions of FE colleges). However, the way that these issues are being framed and addressed varies very considerably across the four nations, as the result of being located inside divergent wider national policy discourses and gaols.

As the various contributors note, if we zoom our focus out from FE and explore wider policy frames and goals then marked differences in national ideological and policy model choices come into view. Northern Ireland is in the odd state of not having a government, but in Cardiff and Edinburgh both administrations are proceeding to fashion over-arching policy narratives around social and economic values and their resultant objectives that are plainly profoundly at odds with what is driving the Conservative government at Westminster. Both the Scottish and Welsh governments are in the process of developing a macro-level policy agenda that emphasises inclusive economic growth, social inclusion, a reduction in inequality, and a long-term focus on sustainability.

In Scotland, which is furthest down this avenue, the Economic Strategy and Labour Market Strategy embody these priorities and the Fair Work Convention and the Scottish Government's Labour Market Strategy Group are evolving policies and ways of measuring their implementation that address issues such as the living wage, employee voice within the workplace, job quality, gender imbalances in the workforce and skills and training for older workers (Keep, 2017). A further manifestation of this approach has been the creation of a single, over-arching board to superintend the work of the economic development agencies and Skills Development Scotland (SDS) and the Scottish Funding Council (SFC) (Gallacher and Reeve, this volume). The objective over time is a much closer integration of the tasks of improving the supply of skills, increasing the demand for skills and ensuring that skills are better utilised within businesses that are more innovative and which have been encouraged to take a 'high road' approach to fashioning their competitive and employment strategies.

In Wales, as James (this volume) discusses, the Future Generations Act provides a set of political values against which all future legislation and public sector action has to be judged and represents an attempt to 'hard wire' a set of over-arching aspirations concerning community, social justice and prosperity into policy thinking. Wales has established a Digital Innovation Commission to explore the impact of digital technologies and AI on work, jobs and skills. It has also just announced a Fair Work Commission to identify policy priorities for work and employment in a way analogous to the Scottish Fair Work Convention.

In England, by way of contrast, while there have been sporadic and fairly vague statements about helping those who are just getting by, re-balancing of the economy (sectorally and spatially), and the creation of an industrial strategy that focuses almost exclusively on high-tech industries rather than the economy and the workforce in general, these developments do not as yet portend any fully worked through or articulated strategic vision about the social and economic contexts in which skills development should be taking place. For example, the limited, slow and halting progress that the 
government has made in responding to and implementing the fairly modest recommendations made by the Taylor Review of modern working practices is indicative of the difficulties - practical and ideological - that confront any attempt to re-think and roll back the flexible labour market that successive UK governments of all political persuasions have argued forms one of the cornerstones of our economic competitiveness. There is nothing like the relatively comprehensive fair work agenda that is to be found in Scotland and which may now be emerging in Wales.

England also no longer possesses much policy machinery at national level for addressing economic development or business improvement and support. It has no national economic development agency, and what development functions exist are fragmented and reside at the level of the Local Economic Partnerships (LEPs) or Mayoral Combined Authorities (MCAs).

All this matters because it leaves English vocational E\&T policy and FE providers operating without the same kind of reference point of broader economic and social goals that their Scottish and Welsh counterparts possess, and indeed without any coherent overall strategy for FE or vocational education more widely (Keep, 2016 and 2018). As David Hughes, the chief executive of the AoC recently observed, there is, for example, no strategy for 16-19 education, just "islands of reform" (Hughes, 2018) - a point echoed by the chief executive of the Learning and Work Institute (Evans, 2018). It also means that, as ever, English skills policy continues to be focused more or less exclusively on issues of supply, with comparatively little concern to focus policy concerns around problems of inadequate demand or poor skills usage (Keep and Mayhew, 2010 and 2014), whereas policy in Scotland, and increasingly now in Wales, has acknowledged that the pattern of demand from employers is also a major issue.

These very different national policy contexts are liable to make policy learning harder, especially between the UK government and the rest of the UK. This is because developments outside England, particularly in Scotland and Wales, are being framed within and driven by macro-level policy concerns that are either absent or weak in England.

\section{Markets or System - a fundamental choice?}

Not only are the national policy backdrops against which these skills policy goals being pursued very different, so too are the means by which delivery of these policies is intended to take place. In Scotland, Wales and Northern Ireland, as the country articles make clear, the central delivery model is that of a national system with elements of local governance and some contestability. In England, there instead has gradually evolved a set of nationally designed and regulated quasi-markets, within which the 'invisible hand' of market forces is expected to maximise the effective use of resources, driving up of standards, and weed out less effective providers (Keep, 2018 and 2019). 
This reliance on markets has wider impacts on the institutional structure of funding and governance in England, and represents a profound schism in approach with that found elsewhere in the UK. For example, whereas Wales has Qualifications Wales (QW), and Scotland has the Scottish Qualifications Authority (SQA), both of which are national qualifications and awarding organisations in the traditional mould, in England all that now exists is a regulator for an assessment and qualifications market (Ofqual). There are thus national philosophical and practical differences in the way that the processes of standards design, assessment and the award of qualifications are conceived of and executed across the UK.

Plainly England's enthusiasm for markets and the other three nations' choice of a systemsbased approach makes policy learning problematic. It erects a fundamental ideological divide which it is difficult to bridge, and it means that funding, governance and organisational models in England are hard to export to the other nations' and vice versa.

\section{The vexed role of employers}

As the individual country articles and Hodgson et al's overview (this volume) illustrate, a common concern is how best to organise and mobilise employers. James (this volume) and Gallagher and Reeve (this volume) note an emphasis within their nation's policy processes on partnership, consultation, dialogue, and attempts to involve stakeholders in policy deliberations in a systemic manner. England has taken a very different approach, where top-down government edict and exhortation have taken the place of more substantive two-way dialogue, and where the main vehicle for social partnership around skills across the UK - the UK Commission for Employment and Skills (UKCES) - was abolished. As a result, even if a structured and sustained conversation with employers, trade unions and other parties were a desired goal, the mechanisms to deliver this at UK and English levels have been swept away.

Having surveyed the backdrop, we now turn to investigate the prospects for policy learning across the four nations. What is the scale of the opportunities on offer?

\section{The scale of opportunities for expansive policy learning across the UK}

Hodgson et al (this volume) argue that a new balance may be emerging between the forces of convergence and divergence across the UK. Is this the case, and if it is are we now on the cusp of a fundamental change in England that will enable a shift towards a more localised focus for policy, the adoption of a High Progression and Skill Ecosystems approach, and also the creation of the circumstances where policy learning across all four UK nations becomes far easier to contrive, as Hodgson and Spours (this volume) argue? For this to occur, they suggest that:

English FE will have to continue its hesitant journey from being a competitive 
and reactive national sector to becoming a strategic part of local and regional learning and skills systems.

(Hodgson and Spours, this volume)

The prospects for the continuance of this journey, they suggest, hangs in the balance.

An analysis of recent policy in England suggests that this trajectory may be possible, provided that national policy narratives and steering mechanisms (e.g. funding and inspection) begin to prioritise collaboration over competition; the roles of local and regional government continue to be strengthened; and that local networks of providers, employers and other social partners grow to address their pressing economic and social agendas.

(Hodgson and Spours, this volume)

Thus their case partially rests on arguments that in England the government may have started to step back from marketisation, thereby reducing the cleavage in policy trajectories between England and the other three nations, and that this is occurring in the context of a renewed interest in localities and a focus upon vocational learning - a vocational 'turn'. These propositions are explored in what follows.

\section{Stepping back from the market?}

One of the problems with policy formulation and delivery in England is its tendency towards incoherency and the existence of a double-shuffle effect (Hall, 2005; Spours, 2017) that sees policy makers trying to obtain what they conceive of as the best of both worlds while deploying fundamentally mutually contradictory policy models (see Keep, 2018 for a discussion of official ambivalence about marketisation). If marketisation has been the two steps forward, what elements now constitute the backward shuffle and how significant are they?

The first are Area Based Reviews (ABRs). As Hodgson and Spours (this volume) argue, the ABRs were an attempt to impose an orderly rationalisation on FE provision and set the remaining colleges up to be financially viable through merger and greater cooperation and a more coordinated approach to particular areas and levels of provision within their local learning marketplaces. Do they also signify a retreat from reliance on market forces? Although at one level they plainly do, it could be argued that this was a temporary phenomenon and that the ABRs were simply an acknowledgement that the combination of austerity and competition meant that many FE colleges lacked a long-term future and that a swifter and more organised rationalisation process than the gradual, messy and uncoordinated collapse of individual colleges was a political necessity (Keep, 2018). It is certainly the case that the ABRs were designed to operate within a tightly defined remit, which for example excluded school VI forms, and were viewed by DfE as a 'one off' that would be followed by a new insolvency regime for colleges. 
In reality, the recommendations from some ABRs have not been implemented and others only partially, and it is now clear that the ABRs did not entirely solve the underlying financial stability issues caused by under-funding as colleges, including large ones, continue to fall into serious financial difficulties (see below). If ABRs were an attempt to draw a line in the sand, the tide of fiscal and competitive reality has continued to advance. In recent conversations with those in FE, the failure to ensure that the ABRs covered both schools and colleges, and the lack of any real coordination between the approaches of the National and Regional Schools Commissioners, and the FE Commissioners has been adduced as evidence that policy is incoherent and that FE is now being squeezed between schools and HE, both of which are felt to have a higher political salience than FE within DfE's thinking, a point to which we now turn.

Indeed, there is a danger of under-estimating the profoundly disruptive scale and nature of the competitive forces that government has unleashed in English education. FE colleges are not simply competing with other colleges, or with independent training providers (ITPs) and a range of adult learning providers in the post-19 marketplace, they are also locked in battle with new school market entrant institutions that often focus their appeal on a vocational offering (e.g. University Technical Colleges [UTCs] and Studio Schools) as well as with pre-existing school VI forms in the 16-19 marketplace and also with higher education institutions (HEIs) (Keep, 2018).

Between 2011/12 and 2014/15 about 260 additional new school VI forms were created, and the AoC claims that more than half of all school VI forms are now operating with pupil numbers below the threshold for viability set by DfE (Hughes, 2018). These schools are therefore heavily incentivised to seek more pupils for their upper secondary phase, sometimes by retaining those better suited to provision outside school and by seeking to deliver elements of vocational learning such as BTECs and the new T levels (Hughes, 2018).

At the same time, lower tariff HEIs are facing a major downturn in applications, in part driven by the expansion of higher tier institutions in the wake of the removal of the student numbers cap, and partly because of a demographic downturn in 18 year olds. As detailed elsewhere (Keep, 2018), the result has been a rise in HEIs moving down the qualifications ladder to embrace more foundation, sub-degree and even level 3 provision in direct competition with their local FE providers, and also in some instances removing accreditation of HE in FE in subject areas where they are seeking to develop degree apprenticeships. Universities UK (UUK, 2018) has recently published a report on FE/HE cooperation around higher level skills and in it, they admit that, in terms of barriers to cooperation:

the competitive space has become more marked with the increasing marketization of HE. This could be universities and competing for HE students, or colleges in competition with each other for local FE or HE students...The importance of higher and degree apprenticeships has 
also arguably contributed to the competitive environment.

Apprenticeships have traditionally been firmly situated within the FE

sector. Universities moving into this space can sometimes be seen as

a threat and detrimental to the likelihood of collaboration.

(UUK, 2018: 25).

This situation is in sharp contrast to that pertaining in Scotland, where SFC and government policies delineate responsibilities. Colleges deliver vocational and sub-degree learning, and HEIs deliver degrees and above, and linkages between sub-degree and higher provision are set via articulation agreements between colleges and their local HEI (Gallacher and Reeve, this volume).

As a result, for a more cooperative system to emerge in England, the new system and the incentives to underpin it would need to bring school VI forms and HEIs into its ambit as well as FE, ITPs and other vocational providers. At present, FE, schools and HE are governed at national levels by entirely separate policy silos within DfE, and to date there have been no signs that the new regulator of HE provision (the Office for Students - OfS) has any interest in co-ordinating the HE marketplace with that in FE. Indeed, its current concern is to ensure a more competitive market for HE that encourages new entrants and challenger institutions rather than any notion of system. Likewise, small school VI forms appear to be politically untouchable at present.

The scale of the resultant competitive pressures and the impacts that they are creating in FE should not be under-estimated. In the course of less than two months this autumn, eight English college principals have been forced to resign, in large part due to the poor financial health of their institutions. These were mainly large colleges, with above average staff and learner numbers and with a combined income of $£ 439$ million in 2016/17 (Burke, 2018a: 16). Moreover, in a single week (1115 November 2018) five colleges were given a 'notice to improve' by the government because of their poor financial health (Camden, 2018a: 6). How the new insolvency regime for colleges in England will impact on this picture is at present unknown, but the government claims that once it is operating, government funding for bailouts will cease (Burke, 2018a; Gravatt, 2018a). Against this somewhat gloomy backdrop, the DfE has established a unit to look at college financial resilience

As Gravatt (2018a) argues, systemic underfunding of much of the provision that English FE deals in means that colleges are under pressure, and this, coupled with the uncertainty and instability engendered by the changing nature of the quasi-market funding regimes that pertain across different segments of FE's activities, makes the task of managing and governing an English FE provider a more uncertain one (Keep, 2018) than is probably the case in the other three nations, where funding is somewhat more predictable.

Instability is also being engendered by sharp practices and in some instances what appears to be outright fraud by some independent training providers (ITPs). This year the two largest English 
ITPs (Learndirect and 3aaa) have gone into administration due to the ESFA turning off funding because of the emergence of evidence of manipulation of various performance metrics by company managers (see Camden, 2018b). In the case of 3aaa there is evidence that public funding for E\&T converted into company profits that supported an extremely lavish lifestyle by the company's owners, as well as the sponsorship of Derbyshire County Cricket Club, and corporate hospitality that included a concert by Sir Elton John (Camden, 2018b). This kind of behaviour seems absent in the other UK nations, where ITPs are smaller and have more carefully delineated roles within the E\&T system. In this respect English experience, sadly, appears to be following that of Australia, where marketisation of TAFE produced significant problems with fraudulent behaviour and low quality provision (Wheelahan, 2016; Ross, 2018 ).

It could be argued that these are merely the teething problems of a vibrant new marketplace, but at present this backdrop forms a radically different environment in which to be running a college than is found in the other three UK nations and their FE systems. This is liable to constrain the space and time needed to build trust between providers and indeed between providers and their stakeholders and to undermine the conditions in which wider cooperation can be sustained.

In terms of an overview, English policy makers are, as is often the case, grappling with contradictory desires. Although many continue to believe in marketisation, the virtues of contestability and the superior resource allocation power of the 'invisible hand' of market forces, there remains a parallel belief by some in national government that it is still possible to engineer a set of incentives that balances elements of cut-throat competition (which results in institutional collapse) with elements of local cooperation. The nature of this balance and the design of the incentives to support the cooperative remain clouded in obscurity, but to some policy makers it appears tantalisingly achievable (Keep, 2018).

There are certainly straws in the wind that suggest some in DfE might favour an element of re-balancing between markets and cooperation. For instance, in a recent speech by the Skills Minister to the Association of College's annual conference, she suggested that she wanted "to see more and more apprenticeship training offered by colleges and where possible, possibly in collaboration with independent training providers" (Camden, 2018c). An interesting sentiment, but one that runs counter to much that her department have spent the last few years doing in terms of creating a market for apprenticeships, into which about 1,200 brand new providers have entered since the levy was announced.

Also, just in case the invisible hand's guidance proves inadequate or misdirected, there is also a hankering to superimpose on the marketplace a 'lite-touch' version of the 'plan and match' model of synchronising skills supply with skills demand that the Learning and Skills Council (LSC) sought to deliver in its early years - witness the proposals for the new Skills Advisory Panels (SAPs), which 
stem from a 2017 Conservative Manifesto proposal. This best of both worlds approach is problematic and the SAPs appear liable to face a difficult birth. They are expected, using largely nationallymanaged data sets (such as the Employers Skills Survey), to generate detailed forecasts of future skill need at Local Enterprise Partnership (LEP) and MCA level, and then use this data to influence the shape of local provision to help meet projected demand. The central problem is that in the LEP areas there are no significant funding incentives available to the SAP or its LEP to support this, and in the MCAs what is left of the devolved adult education budget (AEB) is probably too small to provide a sufficient lever (see below).

Overall, there is not much sign that marketisation is being abandoned. Rather, an argument can be made that the current period in England is not one of a major strategic change in policy direction, but rather one where, as Hodgson and Spours (this volume) term it, policy is "staggering on", and where sometimes incoherent and ad hoc reactions are being made as the implications of marketisation and budget cuts surface and play out, often in ways that were unintended or unanticipated. This is the world of Ball's (1994 and 1998) resort to bricolage within policy. If cooperation is desired, it is cooperation superimposed upon and subordinated to a marketplace, with market forces the fundamental driving value and priority.

It is also worth asking whether colleges themselves are keen to step back from the market. Hodgson and Spours (this volume) appear to assume that those managing FE institutions will be strongly motivated to move towards a cooperative local system. This may not universally be the case. During fieldwork for a FETL project on devolution of the AEB (Keep, 2016) and various dissemination activities that followed, it became apparent that there were senior college managers and governors who welcomed and embraced marketisation, thrived on and were motivated by competition with other providers and saw opportunities for their institution to secure relative advantage through being entrepreneurial and exploiting funding competitions to the fullest extent. They were also extremely unenthusiastic about any return to governance and accountability arrangements that smacked of 're-incorporation'. They preferred the independence and freedom to act within a marketplace, and, as Doel (2018) has observed this preference has material underpinnings: "the instinct towards competition is deeply embedded within further education. Moreover, with the continuing pressure on resources, the risk is that institutional or organisational self-preservation will remain paramount. In such circumstances, the prospect of reciprocity and enduring trust growing organically between providers seems difficult to conceive" (2018: 13).

As Hodgson and Spours (this volume) note, the years since 2004 have witnessed a gradual shift from system to market and one consequence of this relatively lengthy period of marketisation is that for managers who have grown up with this trend, contestability and competition are now the norm or default setting for institutional strategy. It also seems reasonable to assume that in an 
increasingly marketised environment, senior managers who are adept or appear adept at coping with the pressures that this brings will have tended to rise in the profession as they appear more closely in tune with the spirit of the age than those who continue to hanker after a systems-based approach. This suggests that for new localised systems of cooperative behaviour to thrive, a new cadre of senior managers may need to emerge to proselytise for and promulgate the adoption of more collectivist models.

\section{Devolution of skills funding - minor adjustment or major change?}

There is a danger in over-stating the potential of the devolved AEB to change the overall dynamic in English FE from one of market to one of system (Keep, 2016). The devolved AEB is not a vast sum of money. The entire (devolved and un-devolved) AEB is £1.5 billion, and represents about 3.7 per cent of overall UK government spending on education and training. Not all of the AEB comes to colleges, as other providers, such as community learning organisations, are also active in the post-19 field. Of the overall AEB, about $£ 600$ million will be devolved to the seven MCAs:

Liverpool City Region -

Tees Valley -

Greater Manchester -

West Midlands -

West of England -

Cambridge and Peterborough - $£ 12$ million p.a.

Greater London Authority - $\quad £ 311$ million p.a.

(SOURCE: Allen-Kinross and AoC: 2018)

$£ 24$ million p.a.

$£ 90$ million p.a.

$£ 17$ million p.a.
$£ 65$ million p.a.

$£ 105$ million p.a.

The AEB devolution to MCAs also comes with some strings attached, in the shape of pre-existing adult learning entitlements which mean that elements of the funding are nominally devolved, but are already committed to meeting these statutory entitlements. These currently cover literacy and numeracy, but will from 2020 also include basic digital skills (BDS). The BDS entitlement will also come out of the AEB as no new funding is forthcoming, and the Greater London Authority (GLA) calculate that it will reduce their annual discretionary AEB spend by seven to nine per cent (GLA, 2018: 9).

The overall income of English colleges is about $£ 6.1$ billion a year ( 83 per cent of which comes from the public purse - Gravatt, 2018b), with the largest single element being funding for 1618 year olds. The $£ 600$ million from the devolved AEB will be shared between 62 colleges within the MCAs, while the 168 colleges outside these areas will not be directly affected by this at all (AllenKinross, 2018a) and the vast bulk of their public funding will continue to be disbursed nationally. Even in the MCAs, given the multiple existing calls upon it, the AEB does not provide a large amount 
of room to fundamentally re-shape post-19 provision or to embark on radical experiments with new models of provision, and it is an open question whether the incentives it generates will be sufficient to deliver any fundamental change in the dynamics of local provider strategies away from sometimes dog-eat-dog models of competition towards more collaborative modes of engagement.

It is also important to note that, at least for the present, devolution in England has stalled. There is currently no prospect that further devolution of the remaining un-devolved AEB will be offered to the Local Enterprise Partnerships (LEPs). If devolution does not regain momentum, this will lead to a strange patchwork model of post-19 funding and governance whereby people in some large conurbations will have one set of local arrangements, and those residing in smaller towns, cities and rural areas will continue to 'enjoy' national control. Thus the MCAs' attempts to use the AEB to establish localised post-19 skills systems are liable, at best, to create islands of systems thinking in a sea of fragmentation and marketisation.

A final, and as yet unresolved question, is whether there exists any means of establishing a new balance of power between national and local levels. Devolution as yet has not been seen as extending as far as 'dual-key' model of policy formation, where national and local levels need to reach agreement before reforms can proceed (Keep, 2016). This kind of national/local policy space would be a useful arena for helping clarify and perhaps even resolve a range of issues, not the least of which concern the relative merits of the market thinking being advocated by government and systems thinking championed by some of the MCAs. At present, DfE remain unenthusiastic, to say the least, in their response to continued calls from the MCAs for shared control with national level of other aspects of skills funding (e.g. 16-19) or any wider role of influence in policy (Keep, 2016).

\section{A new emphasis on vocational education and training}

The problem with a belief in the occurrence of a vocational turn in policy is that in England we have witnessed many such 'turns' over the past 35 years, and in each case the ideological and values auto pilot that steers national policy has managed to 'correct' the turn and ensure that policy reverts to its traditional course and associated hierarchical focus, with the academic trumping the vocational. Policy rhetoric has certainly flagged up ministerial enthusiasm for vocational offerings apprenticeship and $\mathrm{T}$ levels, but it is profoundly unclear where both policy areas are actually heading. Apprenticeship and $\mathrm{T}$ levels are but the latest in a long line of attempts to develop and then deliver higher status vocational offerings that can act as a counterpart or counterweight to the 'royal route' of A levels. As Richmond (forthcoming) argues, we have been here before with GNVQs, vocational A levels, and the Diploma. Until T levels have been trialled, rolled out and employers, students and parents have made judgements concerning their utility and value, it is hard to know what importance they will really have. As far as apprenticeship is concerned, a separate article would be needed to do 
this topic justice, but the key point is that policy has produced a host of unintended outcomes, many of which are deeply problematic.

At a material level, as the Institute for Fiscal Studies' report (Belfield, Farquharson and Sibieta, 2018) on educational spending lays bare, the college sector in England has, relative to schools and HE, been the loser. Indeed, as Hodgson and Spours (this volume) admit, vocational learning and FE can be portrayed as locked into a trajectory of decline.

In 1990-91, spending per student in further education was 50\% higher than spending per student in secondary schools, but it is now $8 \%$ lower. Spending on further education fell faster during the 1990s, grew more slowly in the 2000s, and has been one of the few areas of education spending to see cuts since $2010 \ldots . .$. the total number of adult learners fell from 4 million in 2005 to about 2.2 million in $2016 \ldots .$. Total funding for adult education and apprenticeships fell by $45 \%$ in real terms between $2009-10$ and $2017-18 \ldots$.."

(Belfield, Farquharson and Sibieta, 2018: 6).

The problem with the idea that we are experiencing a renewed emphasis on the vocational in England is that funding for this form of learning has declined, and no amount of warm words from policy makers (see Hinds, 2018) can compensate for this. Moreover, the dominance of HE continues, and, it could be argued in all of the countries under examination here it remains the royal route and the mode of provision that has been favoured in terms of social status, political capital invested, and public funding committed to it.

\section{Overview}

The foregoing suggests that the halting journey for English policy advanced Hodgson and Spours (this volume) has, as yet, not taken us very far and that the fundamental forces that drive policy divergence and reduce the space for policy learning across the four countries still largely remain in place. If this is the case, what opportunities for learning remain?

\section{Prospects for progress - who might enter and work in the learning laboratory? Practitioner learning}

If the motivation for national policymakers in the UK government to look North or West for inspiration is limited, what other actors in England might want to embark on some learning? One 
answer is that, given the range of common policy challenges and practical issue facing colleges (see Hodgson et al, this volume) it seems entirely plausible that colleges, whether individually or more likely collectively through their national associations, will be motivated to seek to learn from one another and to find common solutions to shared challenges. Colleges are well-positioned and motivated to forge cross-border innovation partnerships focusing on common areas of concern, such as new modes of local provider collaboration, new forms of vocational learning, pedagogy and curriculum development, and models for the co-production of skills with employers (Hodgson et al, this volume). Indeed the four national college associations have already started to talk across national borders and to exploring how to promulgate a broad, shared policy agenda that seeks to reposition FE and vocational learning within and across the UK.

\section{Partial devolution in England - a back door to policy learning}

If the prospects for meaningful policy learning by the UK government seem remote, the arrival of devolution AEB in the MCAs may be opening up a new level at which policy exchange could occur. In terms of scale, one of the MCAs (London, with 8.78 million inhabitants) has a larger population and level of economic activity than any of the devolved nations, and Greater Manchester, with 2.79 million people is not far behind Wales (3.11 million) and larger than Northern Ireland (1.8 million).

Perhaps more importantly, some of the MCAs are starting to attempt the development of integrated policies that address job quality, fair work and a living wage, progression in employment, a local industrial strategy, innovation, business support and improvement, and skills. In other words they are treading the same path as Wales is starting to follow and which has already been taken by Scotland. This provides a broad-based common agenda and range of challenges around which learning about skills and many other areas of policy development could be focused. That a learning laboratory or 'policy club' approach might emerge is made all the more likely by the fact that finding effective ways to integrate the different policy areas across skills, employment, the labour market and economic development and business improvement is far from easy, and learning from the experience of others operating in a close comparison environment could prove an attractive prospect. Joint capacity building to support these policies is another area where activity could emerge.

\section{Inter-governmental learning}

As argued above, at present the prospects for this are bleak, at least if English involvement is desired. Besides the difficulties already outlined, one of the key problems is the absence of well-established and well-used institutional mechanisms or conduits through which interchange between the four national governments and their respective skills agencies could be conducted (McEwen et al, 2018). Travelling around the UK and meeting civil servants and agency staff, the author has often been struck by the absence of any awareness of policy developments in adjacent jurisdictions across 
common areas of concern (e.g. apprenticeships). This reflects the hard reality that funding cuts and staffing reductions have hit the civil service in all four nations hard and that at present the mechanisms and routines that might enable information flows are weak and patchy. As a result essential pre-requisites for policy learning in the shape of capacity and institutional support are lacking.

England also lacks well-established and expert intermediary bodies in the skills field that could assist in this inter-country learning process. Wales is creating a tertiary funding council, Scotland has SDS and the SFC, England has nothing comparable and has just abolished the last of its powerful educational intermediaries (in the shape of the Higher Education Funding Council for England - HEFCE). What England has instead are market regulators (Ofsted, and the Education and Skills Funding Agency - ESFA) which have a much narrower role and capabilities. Thus if England wanted to move to a more concerted, coordinated systems approach the intermediary institutions to make this happen are absent. Capacity is also a problem at local levels, where the MCAs are struggling to put in place the means to administer the AEB. Broader objectives will remain hard to deliver without a major investment in creating new capacity to join up policy agendas.

\section{Final thoughts}

Learning across and between the three devolved nations is possible and desirable, and also between the devolved nations and the English MCAs. Learning between the devolved nations' FE colleges (individually and collectively) is possible and desirable. The point at which progress becomes hard to envisage is at the level of the UK government, for reasons outlined above. At present, three options seem to be on the table. Policy continuity around a reliance on markets with an overlay of hopes concerning limited cooperation continues, marketisation further intensifies, or a swing towards further devolution and the re-invention of mechanisms for local democratic accountability that ushers in a more cooperation, systems-based approach. 


\section{References}

Allen-Kinross, P. 2018. "London Mayor seeks special treatment amid AEB postcode lottery concerns”, FE Week, Edition 263, 30 November, pages 10-11.

Ball, S. J. 1994. Education reform: a critical and post-structural approach, Buckingham: OU Press.

Ball, S. J. 1998. "Big Policies/Small World: An introduction to international perspectives in education policy", Comparative Education, 34 (2), 119-130.

Belfield, C., Farquharson, C., and Sibieta, L. 2018. 2018 Annual Report on Educational Spending in England, London: Institute for Fiscal Studies.

Burke, J. 2018. "What is behind the spate of resignations of college leaders?", FE Week, 16 November, 16-17.

Camden, B. 2018a. "Five colleges handed DfE warnings over finances", FE Week, 16 November, page 6 .

Camden, B. 2018b. "Police focus on 3aaa dodgy data and use of apprenticeship grant for employers", FE Week, 16 November, 10-11.

Camden, B. 2018c. "Milton DOES want collaboration between colleges and private providers, DfE confirms", FE Week, Edition 263, 30 November, page 16.

Doel, M. 2018. "Provocation: Competition and Collaboration in Further Education", FETL Professor Roundtable on Prospects for Collaboration as well as Competition in Further Education?, London, 26 September.

Evans, S. 2018. "Lessons from Tory conference: next steps for FE and skills", FE Week, Edition 256, 5 October, page 15

Gravatt, J. 2018a. "The restructuring of colleges is complex, secretive and costly", FE Week, 16 November, page 24.

Gravatt, J. 2018b. "What governors need to know about funding", AoC Governors Conference, 14 March, London: Association of Colleges.

Greater London Authority. 2018. Skills for Londoners Framework, London: GLA.

Hall, S. 2005. "New Labour's double shuffle”, Review of Education, 27 (4), 319-335.

Hinds, D. 2018. "FE colleges are the 'national infrastructure' for tech ed", FE Week, Edition 264, 7 December, page 19.

Hughes, D. 2018. Presentation at the Skills, Employment and Inclusive Growth Conference, Local Government Association, London, 27 November.

Keep. 2016. "The Long-Term Implications of Devolution and Localism for FE in England", AoC/SKOPE research on localism final report, London: Association of Colleges. 
Keep, E. 2017. "English exceptionalism re-visited: divergent skill strategies across England and Scotland", Journal of Education and Work, 30 (7), 741-749.

Keep, E. 2018. Scripting the Future, FETL Monograph, Tetbury: Further Education Trust for Leadership.

Keep, E. 2019. "FE colleges in England and the skills policy agenda", in J. Gallacher, and F. Reeve (eds.), New Frontiers for College Education - International Perspectives, London: Routledge, 61-76.

Keep, E, and Mayhew, K. 2010. "Moving Beyond Skills as a Social and Economic Panacea?", Work, Employment and Society., 24 (1), 565-577.

Keep, E., and Mayhew, K. 2014. 'Inequality - 'wicked problems', labour market outcomes and the search for silver bullets", Oxford Review of Education, 40 (6), 764-781.

Kwarteng, K. 2015. Towards 2025, London: Free Enterprise Group.

McEwen, N., Kenny, M., Sheldon, J., and Brown Swan, C. 2018. Reforming Intergovernmental Relations in the United Kingdom, Cambridge: Bennett Institute of Public Policy.

Richmond, T. (forthcoming). A Qualified Success - An investigation into T-levels and the wider vocational system, London: Policy Exchange.

Ross, J. 2018. "Turning the ship around”, Australian TAFE Teacher, 51 (1), 8-10.

Spours, K. 2017. Mayism without May? The crisis of the regressive alliance and the challenge of Corbynism. London: Compass.

Universities UK. 2018. Routes to High-Level Skills, London: UUK.

Wheelahan, L. 2016. "Patching bits won't fix vocational education in Australia - a new model is needed", International Journal of Training Research, http://dx.doi.org/10.1080/14480220.2016.1254268 